\title{
The effect of frequency and mode of sports activity on the psychological status in tetraplegics and paraplegics
}

\author{
S Muraki*,1, N Tsunawake ${ }^{1}$, S Hiramatsu ${ }^{2}$ and M Yamasaki ${ }^{3}$ \\ ${ }^{1}$ Department of Nutrition and Health Sciences, Faculty of Nursing and Nutrition, Siebold University of Nagasaki, \\ Japan; ${ }^{2}$ Department of Physical Education, Onomichi Junior College, Japan; ${ }^{3}$ Department of Health Science, Faculty \\ of Integrated Arts and Sciences, Hiroshima University, Japan
}

\begin{abstract}
Objective: To examine whether the psychological benefits of sports activity differ between tetraplegics and paraplegics with spinal cord injury, and investigate the effect of frequency and modes of sports activity on the psychological benefits.

Methods: The Self-rating Depression Scale (SDS), State-Trait Anxiety Inventory (STAI) and Profiles of Mood States (POMS) were administered to 169 male individuals with spinal cord injury (mean age $=42.7$ years) including 53 tetraplegics and 116 paraplegics. The subjects were divided into four groups according to their frequencies of sports activity; High-active (more than three times a week; $n=32$ ), Middle-active (once or twice a week, $n=41$ ), Low-active (once to three times a month, $n=32$ ), and Inactive (no sports participation, $n=64$ ).

Results: Analysis of variance revealed significant differences in depression for SDS, trait anxiety for STAI and depression and vigor for POMS among the groups. High-active group showed the lowest scores of depression and trait anxiety and the highest score of vigor among the four groups. In contrast, no significant difference was found for any psychological measurements between tetraplegics and paraplegics. In addition, there was no significant difference for any psychological measurements among modes (wheelchair basketball, wheelchair racing, wheelchair tennis and minor modes).

Conclusions: These findings demonstrated that sports activity can improve the psychological status, irrespective of tetraplegics and paraplegics, and that the psychological benefits are emphasized by sports activity at high frequency.
\end{abstract}

Spinal Cord (2000) 38, 309-314

Keywords: spinal cord injury; sports activity; mood; depression; anxiety

\section{Introduction}

Individuals with spinal cord injury (ISCI) have variable psychological problems even after social return. Previous studies reported that ISCI showed higher incidence of depression ${ }^{1,2}$ and anxiety, ${ }^{1,3}$ and lower quality of life, ${ }^{4}$ compared with able-bodied persons. Accordingly, it is important to develop methods for improving the psychological status in ISCI.

Sports activity may be one of the methods for improving the psychological status in ISCI. Many investigations ${ }^{5,6}$ in able-bodied persons supported the psychological benefits of sports activity on mental health including reduction of stress, ${ }^{7-9}$ depression ${ }^{10,11}$ and anxiety, ${ }^{12-14}$ and on improvement of mood. ${ }^{15,16}$ However, few studies have investigated the effects of sports activity on psychological status in ISCI. ${ }^{17-19}$ Jacobs et $a l^{18}$ and Paulsen et $a l^{19}$ reported better

*Correspondence: S Muraki, Department of Nutrition and Health Sciences, Faculty of Nursing and Nutrition, Siebold University of Nagasaki, 822 Yoshimutago Nagayocho Nishisonogi-gun, Nagasaki 851-2195 Japan psychological profiles in wheelchair athletes compared with non-athletes. However, Foreman et $a l^{17}$ failed to show any significant difference of psychological measurements between sports participants and nonparticipants with spinal cord injury. Thus, there has been a notable discrepancy of psychological benefits among previous studies.

Furthermore, these previous studies ${ }^{17-19}$ investigated the psychological benefits in ISCI without distinction between tetraplegics and paraplegics. The psychological benefits may differ between tetraplegics and paraplegics, since intensity and physiological response of sports activity in tetraplegics are different from that in paraplegics. ${ }^{20,21}$ In addition, it is possible that the mode of sports activity influences the psychological benefits. In able-bodied persons, it is suggested that the psychological benefits differ among modes and intensity of physical activity. ${ }^{6,22-24}$ However, there are no investigations which have examined the psychological benefits related to conditions of injury and mode and intensity of sports activity. 
The aim of the present study, therefore, was twofold: to examine the psychological benefits of sports activity in both tetraplegics and paraplegics with spinal cord injury; and to investigate the effects of mode and intensity of sports activity on the psychological benefits in ISCI.

\section{Methods}

\section{Subjects}

Five hundred ISCI living in the Western part of Japan, including the districts of Chugoku, Shikoku, and Kyushu were mailed a questionnaire, which was specifically designed for this study. All of them had finished a rehabilitation program at a hospital and lived in the community. A total of 269 ISCI responded to the questionnaire. The response rate was $53.8 \%$.

In ISCI over 60 years old and female ISCI, the rates of participation for sports activity were very low. Accordingly, to exclude influence of the age and sex on psychological status, we removed their data from analysis, which left 169 male ISCI whose ages were between 18 and 59 years.

Both tetraplegics and paraplegics were divided into four groups according to the frequency of sports activity for recent months: High-active group (three times a week or more), Middle-active group (once or twice a week), Low-active group (once to three times a month) and Inactive group (no sports participation). Table 1 presents the characteristics of the four groups. Paraplegics showed higher sports participation compared with tetraplegics.

Furthermore, to clarify the influence of sports mode on psychological status, we focused on subjects who participated in sports activity at least 1 day a week; High- and Middle-active groups. The subjects in the High- and Middle-active groups were classified according to the mode of sports activity they performed most frequently; wheelchair basketball $(n=22)$, wheelchair racing $(n=19)$, wheelchair tennis $(n=14)$ and minor modes $(n=18)$. The minor modes included archery $(n=7)$, gate ball (Japanese croquet, $n=3)$, wheelchair table tennis $(n=3)$ and so on. In addition, the subjects of these groups were requested to answer the frequency, duration and intensity of the mode. The intensity was answered using Borg's ratings of perceived exertion ${ }^{25}$ on scales from 6 to 20 .
Assessment of psychological status

The psychological status during a recent month was assessed using three psychometric instruments, a Zung self-rating depression scale (SDS), ${ }^{26}$ a State-Trait Anxiety Inventory (STAI) ${ }^{27}$ and a Profile of Mood States (POMS). ${ }^{28}$ In a lot of studies using able-bodied persons, these instruments have been often used to assess the psychological profiles of athletes and nonathletes and the changes by physical activity. ${ }^{15,22,24}$

The SDS is widely used as a self-report measure of severity of depression, and consists of 20 items; 10 worded positively and 10 negatively. The individual responds to each item on a 4 point scale $(1=a$ little of the time to $4=$ most of the time).

The STAI was used to assess state (20 items) and trait (20 items) anxiety, which were on a 4 point scale (1 to 4). State anxiety refers to the experience of anxiety and tension at the time the questionnaire was completed (ie, how the subject feels 'now'), whereas trait anxiety refers to the general level of anxiety (ie, how the subject 'usually' feels). The score $(20-80)$ is the sum of the individual item scores in each state.

The POMS was used to assess the mood state and consisted of 65 items, which were on a 5 point scale $(0=$ Not at all to $4=$ Extremely $)$. Each item was classified as six sub-scores for tension (9 items), depression (15 items), anger (12 items), vigor (8 items), fatigue (7 items) and confusion (7 items).

In all measurements, each psychological status was assessed by the sum of the individual item scores (Table 2); higher scores represent negative psychological states, except for vigor of POMS.

Table 2 Compositions of three psychiatric measurements (SDS, STAI and POMS)

\begin{tabular}{lcccr}
\hline Instruments & $\begin{array}{c}\text { Measured } \\
\text { state }\end{array}$ & $\begin{array}{c}\text { The number } \\
\text { of items }\end{array}$ & $\begin{array}{c}\text { Scale } \\
\text { (points) }\end{array}$ & $\begin{array}{c}\text { Range of } \\
\text { score }\end{array}$ \\
\hline SDS & Depression & 20 & $1-4(4)$ & $20-80$ \\
STAI & State anxiety & 20 & $1-4(4)$ & $20-80$ \\
& Trait anxiety & 20 & $1-4(4)$ & $20-80$ \\
POMS & Tension & 9 & $0-4(5)$ & $0-36$ \\
& Depression & 15 & $0-4(5)$ & $0-60$ \\
& Anger & 12 & $0-4(5)$ & $0-48$ \\
& Vigor & 8 & $0-4(5)$ & $0-32$ \\
& Fatigue & 7 & $0-4(5)$ & $0-28$ \\
& Confusion & 7 & $0-4(5)$ & $0-28$ \\
\hline
\end{tabular}

Table 1 The characteristics of High-active, Middle-active, Low-active and Inactive groups

\begin{tabular}{|c|c|c|c|c|c|c|c|}
\hline \multirow[b]{2}{*}{ Variable } & & & \multicolumn{4}{|c|}{ Group } & \multirow[b]{2}{*}{ Total } \\
\hline & & & High-active & Middle-active & Low-active & In-active & \\
\hline$n$ & & & 32 & 41 & 32 & 64 & 169 \\
\hline \multirow[t]{2}{*}{ Neurologic status } & Tetraplegics & $(n)$ & 7 & 7 & 9 & 30 & 53 \\
\hline & Paraplegics & $(n)$ & 25 & 34 & 23 & 34 & 116 \\
\hline \multirow[t]{2}{*}{ Age } & Mean & (years) & 41.3 & 42.3 & 42.2 & 43.8 & 42.7 \\
\hline & $\mathrm{SD}$ & (years) & 10.1 & 10.5 & 11.0 & 8.6 & 10.2 \\
\hline
\end{tabular}


Statistical analysis

Each psychological variable was analyzed using twoway analysis of variance (ANOVA) across four groups (High-active, Middle-active, Low-active and Inactive) between tetraplegics and paraplegics. In subject included in the High- and Middle-active groups, a one-way ANOVA was performed for each psychological variable, the frequency, duration and self-reported intensity among four modes (wheelchair basketball, wheelchair racing, wheelchair tennis and minor modes). When a significant main effect was observed, post-hoc analysis was conducted using Tukey's test. A $P$-value of less than 0.05 was regarded as statistically significant.

\section{Results}

Table 3 shows scores for the measured psychological variables of the four groups in tetraplegics and paraplegics. No significant difference was found for any variables between tetraplegics and paraplegics (Table 4). However, there were significant differences for scores of depression for SDS, trait anxiety for STAI and depression and vigor for POMS among the four groups (Table 4). Figure 1 illustrates the comparison of these variables among the groups. Higher frequency of sports activity indicated lower scores of depression for SDS and POMS and trait anxiety for STAI. In vigor for POMS, the High-active group showed a significantly higher score than the other three groups.

Table 5 presents the frequency, self-reported intensity and duration among the four sports modes in subjects included in the High- and Middle-active groups. Significant effects for modes were found for all variables; the frequency $(\mathrm{F}=6.07, \quad P<0.01)$, the intensity $(\mathrm{F}=5.26, P<0.01)$ and duration $(\mathrm{F}=4.27$, $P<0.01)$. The intensity was significantly lower in minor modes than wheelchair basketball. However, minor modes showed significantly higher frequency compared with wheelchair basketball. Moreover, the duration of minor modes was significantly longer than that of wheelchair racing. Table 6 shows the scores of each psychological variable among the four modes. No significant difference was observed for any psycholo-

Table 4 Results of two-way ANOVA for effects of sports activity and neurologic status on psychological measurements

\begin{tabular}{|c|c|c|c|c|c|}
\hline \multirow{2}{*}{\multicolumn{3}{|c|}{$\begin{array}{l}\text { Psychological } \\
\text { measurements }\end{array}$}} & \multicolumn{2}{|c|}{ Factor } & \multirow[b]{2}{*}{$\begin{array}{l}\text { Inter- } \\
\text { action }\end{array}$} \\
\hline & & & $\begin{array}{c}\text { Sport } \\
\text { activity }^{a}\end{array}$ & $\begin{array}{l}\text { Neuro- } \\
\text { gic status }\end{array}$ & \\
\hline SDS & Depression & $\mathrm{f}$ & $7.73 * *$ & 0.05 & 0.64 \\
\hline \multirow{2}{*}{ STAI } & State anxiety & $\mathrm{f}$ & 2.30 & 0.36 & 0.88 \\
\hline & Trait anxiety & $\mathrm{f}$ & $2.79 *$ & 0.30 & 0.25 \\
\hline \multirow[t]{6}{*}{ POMS } & Tension & $\mathrm{f}$ & 1.08 & 0.26 & 0.44 \\
\hline & Depression & $\mathrm{f}$ & $3.72 *$ & 1.87 & 0.45 \\
\hline & Ânger & $\mathrm{f}$ & 1.13 & 0.63 & 0.20 \\
\hline & Vigor & $\mathrm{f}$ & $10.3 * *$ & 0.33 & 1.96 \\
\hline & Fatigue & $\mathrm{f}$ & 2.32 & 1.02 & 0.13 \\
\hline & Confusion & $\mathrm{f}$ & 1.84 & 0.29 & 1.19 \\
\hline
\end{tabular}

${ }^{\text {a }}$ Sports activity is divided into four groups; High-active, Middle-active, Low-active and Inactive; ${ }^{5}$ Neurologic status is divided into two groups; tetraplegics and paraplegics; $* P<0.05 ; * * P<0.01$

Table 3 Score of SDS, STAI and POMS tests among High-active, Middle-active, Low-active and Inactive groups in tetraplegics and paraplegics

\begin{tabular}{|c|c|c|c|c|c|}
\hline Variables & & High-active & Middle-active & Low-active & Inactive \\
\hline \multicolumn{6}{|c|}{ Tetraplegics $(n=53)$} \\
\hline$n$ & & 7 & 7 & 9 & 30 \\
\hline SDS & Depression & $38.2 \pm 2.9$ & $40.0 \pm 10.5$ & $45.3 \pm 7.5$ & $46.4 \pm 7.1$ \\
\hline \multirow[t]{2}{*}{ STAI } & State anxiety & $39.7 \pm 6.5$ & $40.4 \pm 12.0$ & $46.1 \pm 5.9$ & $44.2 \pm 9.0$ \\
\hline & Trait anxiety & $37.6 \pm 11.9$ & $42.0 \pm 15.9$ & $44.4 \pm 11.8$ & $45.1 \pm 10.1$ \\
\hline \multirow[t]{6}{*}{ POMS } & Tension & $10.2 \pm 1.5$ & $11.3 \pm 7.0$ & $13.1 \pm 6.1$ & $13.2 \pm 7.1$ \\
\hline & Depression & $10.2 \pm 8.4$ & $16.7 \pm 15.0$ & $20.9 \pm 14.1$ & $18.5 \pm 10.9$ \\
\hline & Anger & $9.4 \pm 4.6$ & $10.7 \pm 8.4$ & $8.0 \pm 4.6$ & $10.4 \pm 7.0$ \\
\hline & Vigor & $22.2 \pm 4.7$ & $17.0 \pm 8.6$ & $13.3 \pm 5.7$ & $12.7 \pm 5.6$ \\
\hline & Fatigue & $4.8 \pm 5.3$ & $6.4 \pm 7.9$ & $8.1 \pm 8.5$ & $7.5 \pm 5.6$ \\
\hline & Confusion & $7.2 \pm 5.4$ & $7.9 \pm 5.6$ & $10.1 \pm 4.9$ & $9.9 \pm 4.2$ \\
\hline \multicolumn{6}{|c|}{ Paraplegics $(n=116)$} \\
\hline$n$ & & 25 & 34 & 23 & 34 \\
\hline SDS & Depression & $38.4 \pm 7.0$ & $42.6 \pm 7.7$ & $42.1 \pm 7.6$ & $47.4 \pm 7.4$ \\
\hline \multirow[t]{2}{*}{ STAI } & State anxiety & $39.0 \pm 6.8$ & $43.5 \pm 8.8$ & $41.1 \pm 8.1$ & $45.6 \pm 9.4$ \\
\hline & Trait anxiety & $37.7 \pm 7.2$ & $41.2 \pm 9.6$ & $40.6 \pm 9.4$ & $44.8 \pm 11.3$ \\
\hline \multirow[t]{6}{*}{ POMS } & Tension & $9.1 \pm 5.1$ & $11.2 \pm 6.2$ & $10.7 \pm 5.6$ & $12.3 \pm 7.1$ \\
\hline & Depression & $10.0 \pm 4.2$ & $15.0 \pm 9.5$ & $13.8 \pm 7.3$ & $21.1 \pm 12.2$ \\
\hline & Anger & $7.1 \pm 5.1$ & $9.0 \pm 6.0$ & $8.8 \pm 6.9$ & $11.9 \pm 8.8$ \\
\hline & Vigor & $18.0 \pm 5.4$ & $14.5 \pm 5.5$ & $15.3 \pm 5.6$ & $10.6 \pm 5.2$ \\
\hline & Fatigue & $3.4 \pm 3.1$ & $6.4 \pm 5.8$ & $6.4 \pm 4.6$ & $9.3 \pm 7.2$ \\
\hline & Confusion & $6.4 \pm 2.6$ & $8.2 \pm 3.8$ & $7.7 \pm 3.4$ & $8.8 \pm 4.7$ \\
\hline
\end{tabular}


gical variables among the modes, although there were significant effects for the frequency, intensity and duration.

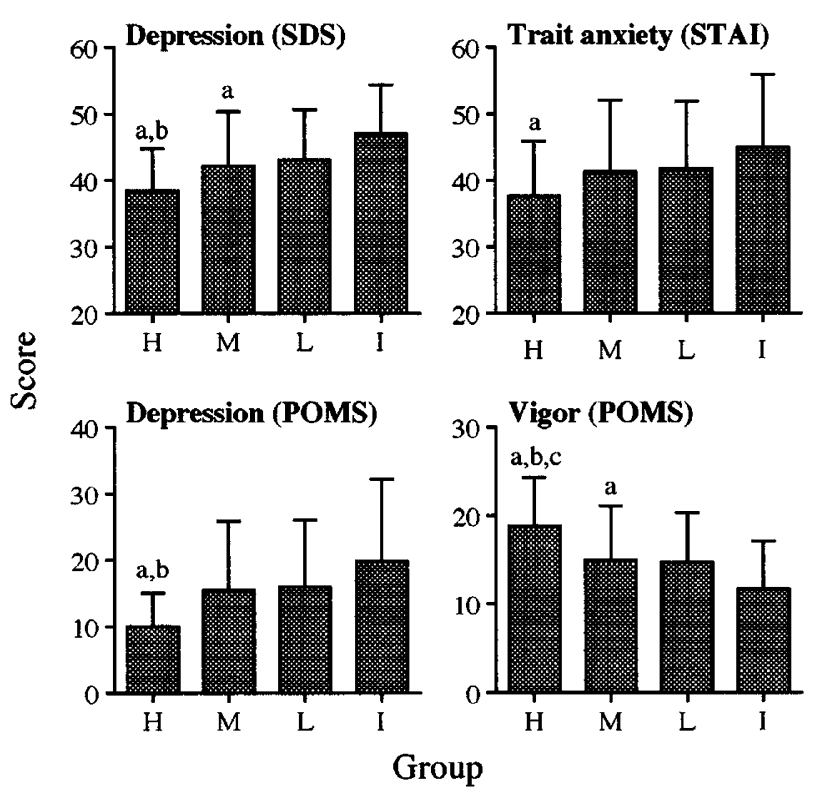

Figure 1 The score of depression for the SDS test, trait anxiety for the STAI test, and depression and vigor for the POMS test among the High-active (H), Middle-active (M), Low-active (L) and Inactive (I) groups in tetraplegics and paraplegics subjects. ${ }^{\text {a }} P<0.05$ compared with Inactive group; ${ }^{b} P<0.05$ compared with Low-active group; ${ }^{\mathrm{c}} P<0.05$ compared with Middle-active group

\section{Discussion}

In the present study, higher frequency of sports activity in ISCI showed better psychological status, especially reductions of depression and trait anxiety and an increase in vigor. These findings were approximately in agreement with those of Jacobs et $a l^{18}$ and Paulsen et $a l,{ }^{19}$ which supported the psychological benefits of sports activity in ISCI. However, Foreman et $a l^{17}$ reported no significant difference in depression between sports participants and non-participants. The difference of these findings was considered to be associated with the psychological instruments used. In the study of Foreman et $a l^{17}$ the degree of depression was assessed using the Centre for Epidemiological Studies Depression Scale (CES-D), unlike the present study which used SDS, STAI and POMS. As far as we know, no study using the CES-D test has demonstrated a positive effect of physical activity on depression. In contrast, many studies using SDS, STAI and POMS reported a decrease in depression by physical activity in able-bodied persons. ${ }^{12,22,29-32}$ Accordingly, the CES-D test used by Foreman et $a l^{17}$ may not clarify the effect of sports activity on depression.

In ISCI, regular sports activity did not necessarily lead to better scores in all sub-scores for POMS. The present study failed to show significant differences in tension, anger, fatigue and confusion among groups, whereas there were significant differences for depression and vigor. In the study of Jacobs et al, ${ }^{18}$ significant differences between wheelchair athletes and non-athletes were found only in depression and vigor in six sub-scores for POMS, which was in

Table 5 Intensity, frequency and duration of activity for four modes; wheelchair basketball, wheelchair racing, wheelchair tennis and minor modes

\begin{tabular}{|c|c|c|c|c|c|}
\hline Variables & $\begin{array}{l}\text { Basketball (B) } \\
(\mathrm{n}=22)\end{array}$ & $\begin{array}{l}\text { Racing }(R) \\
(\mathrm{n}=19)\end{array}$ & $\begin{array}{l}\text { Tennis }(T) \\
(\mathrm{n}=14)\end{array}$ & $\begin{array}{l}\text { Minor }(M) \\
\quad(\mathrm{n}=18)\end{array}$ & $\begin{array}{c}\text { Significant } \\
(P<0.05)\end{array}$ \\
\hline Intensity (Borg's RPE scale: $6-20$ ) & $15.8 \pm 1.7$ & $15.1 \pm 2.3$ & $13.5 \pm 2.7$ & $12.8 \pm 3.0$ & $\mathrm{~B}>\mathrm{M}$ \\
\hline Frequency (days per week) & $2.1 \pm 0.6$ & $3.4 \pm 1.9$ & $1.9 \pm 0.6$ & $3.6 \pm 2.0$ & $\mathrm{R}, \mathrm{M}>\mathrm{B}, \mathrm{T}$ \\
\hline Duration (min per day) & $125.8 \pm 42.1$ & $52.4 \pm 27.0$ & $124.6 \pm 57.3$ & $153.6 \pm 166.1$ & $\mathrm{~B}, \mathrm{M}>\mathrm{R}$ \\
\hline
\end{tabular}

Table 6 The score of SDS, STAI and POMS tests among four modes of sports activity in subjects included in the High-active and Middle-active groups

\begin{tabular}{|c|c|c|c|c|c|}
\hline $\begin{array}{l}\text { Psychological } \\
\text { measurements }\end{array}$ & & $\begin{array}{l}\text { Basketball } \\
(\mathrm{n}=22)\end{array}$ & $\begin{array}{l}\text { Racing } \\
(\mathrm{n}=19)\end{array}$ & $\begin{array}{l}\text { Tennis } \\
(\mathrm{n}=14)\end{array}$ & $\begin{array}{c}\text { Minor } \\
(\mathrm{n}=18)\end{array}$ \\
\hline SDS & Depression & $41.6 \pm 6.6$ & $39.7 \pm 6.0$ & $41.8 \pm 8.4$ & $39.1 \pm 9.9$ \\
\hline \multirow[t]{2}{*}{ STAI } & State anxiety & $41.8 \pm 8.1$ & $41.9 \pm 7.1$ & $42.7 \pm 7.2$ & $39.3 \pm 10.9$ \\
\hline & Trait anxiety & $38.8 \pm 8.6$ & $42.3 \pm 8.0$ & $41.0 \pm 8.8$ & $37.5 \pm 13.1$ \\
\hline \multirow[t]{6}{*}{ POMS } & Tension & $10.1 \pm 5.0$ & $10.4 \pm 5.7$ & $11.2 \pm 4.4$ & $10.5 \pm 7.6$ \\
\hline & Depression & $12.5 \pm 6.4$ & $13.5 \pm 8.8$ & $13.5 \pm 8.2$ & $13.4 \pm 13.0$ \\
\hline & Anger & $7.0 \pm 4.6$ & $8.1 \pm 5.9$ & $9.7 \pm 5.2$ & $10.1 \pm 7.6$ \\
\hline & Vigor & $16.8 \pm 7.0$ & $15.1 \pm 5.5$ & $15.5 \pm 5.3$ & $18.3 \pm 6.1$ \\
\hline & Fatigue & $5.4 \pm 5.0$ & $4.7 \pm 5.3$ & $5.6 \pm 4.8$ & $5.4 \pm 6.6$ \\
\hline & Confusion & $8.1 \pm 3.2$ & $7.1 \pm 4.0$ & $7.4 \pm 2.9$ & $7.1 \pm 5.1$ \\
\hline
\end{tabular}


agreement with the findings of the present study. In contrast, in some previous studies using able-bodied subjects, significant effects of regular physical activity were found for tension, anger, fatigue and confusion as well as depression and vigor. ${ }^{12,32,33}$ Therefore, these findings suggested that participation of wheelchair sports is useful for ISCI and leads to less depression and more vigor in six mood states for POMS.

Psychological benefits of sports activity differed between tetraplegics and paraplegics. In tetraplegics, the relatively small muscle mass employed during the physical activity cannot maintain a high intensity for a long duration. ${ }^{20,21}$ Accordingly, absolute exercise intensity during sports activity in tetraplegics must be lower than that in paraplegics. However, the present study showed marked psychological benefits of sports activity in tetraplegics as well as paraplegics. These findings imply that tetraplegics could sufficiently obtain psychological benefits of sports activity within an exercise intensity at which they can perform.

The psychological benefits of sports activity became more prominent when the frequency exceeded three times or greater per week, as indicated by Figure 1. It is possible that greater benefits in the High-active group were emphasized by physical improvements. In previous studies in ISCI, arm training with a frequency over three times a week indicated physical adaptations such as an increase in physical work capacity, ${ }^{34-37}$ whereas that of lower frequency failed to show the adaptations. $^{38}$ Thus, the degree of the psychological benefits against the frequency of physical activity was approximately consistent with that of physical benefits. These findings suggested that the psychological benefits contributed to physical adaptation caused by sports activity.

However, the present study failed to find differences in any psychological variables among the four modes of sports activity. In previous studies, it had been reported that wheelchair basketball ${ }^{18}$ and track-field ${ }^{19}$ athletes showed better psychological benefits compared with inactive wheelchair users. The findings of the present study also suggest that wheelchair tennis and minor modes have psychological benefits as well as wheelchair basketball and racing. However, minor modes showed significantly lower intensity than wheelchair basketball. In able-bodied persons, it has been well known that vigorous physical activity is suitable to gain psychological benefits, ${ }^{6,22}$ which is not consistent with the findings of the present study. This suggests that the psychological benefits of minor modes was compensated by their higher frequency and longer duration.

In conclusion, sports activity in both tetraplegics and paraplegics can provide desirable psychological status including reduction in depression and trait anxiety and increase in vigor. Moreover, these psychological benefits of sports activity were emphasized in higher frequency participants, especially over three times per week. However, the influences of mode and intensity on the psychological benefits were weaker than that of the frequency.

\section{Acknowledgements}

This research was supported in part by the Descente and Ishimoto Memorial Foundation for the Promotion of Sports Science, Japan.

\section{References}

1 Hancock KM et al. Anxiety and depression over the first year of spinal cord injury: a longitudinal study. Paraplegia 1993; 31: $349-357$.

2 MacDonald MR, Nielson WR, Cameron MGP. Depression and activity patterns of spinal cord injured persons living in the community. Arch Phys Med Rehabil 1987; 68: 339-343.

3 Somasundaram O, Balakrishnan S, Ravindran OS, Shanmugasundaram TK. A psychological study of spinal cord injured patients involved in the Madras Paraplegia Project. Paraplegia 1992; 30: 799-802.

4 Westgren N, Levi R. Quality of life and traumatic spinal cord injury. Arch Phys Med Rehabil 1998; 79: 1433-1439.

5 Folkins $\mathrm{CH}$, Sime WE. Physical fitness training and mental health. Am Psychol 1981; 36: 373-389.

6 International Society of Sports Psychology. Physical activity and psychological benefits: a position statement. Sport Psychologist 1992; 6: $199-203$.

7 Crews DJ, Landers DM. A meta-analytic review of aerobic fitness and reactivity to psychosocial stressors. Med Sci Sports Exerc 1987; 19: S114-S120.

8 Roth DL, Holmes DS. Influence of physical fitness in determining the impact of stressful life events on physical and psychologic health. Psychosom Med 1985; 47: 164-173.

9 Roth DL, Holmes DS. Influence of aerobic exercise training and relaxation training on physical and psychologic health following stressful life events. Psychosom Med 1987; 49: 355-365.

10 Greist $\mathrm{JH}$ et al. Running as treatment for depression. Compre Psychiatry 1979; 20: $41-54$.

11 Martinsen EW. Benefits of exercise for the treatment of depression. Sports Med 1990; 9: 380-389.

12 Blumenthal JA, Williams RS, Needels TL, Wallace AG Psychological changes accompany aerobic exercise in healthy middle-aged adults. Psychosom Med 1982; 44: 529-536.

13 Francis KT, Carter R. Psychological characteristics of joggers. $J$ Sports Med 1982; 22: 386-391.

14 Morgan WP, Roberts JA, Brand FR, Feinerman AD Psychological effect of chronic physical activity. Med Sci Sports Exerc 1970; 2: 213-217.

15 Folkins CH. Effects of physical training on mood. J Clin Psychol 1976; 32: $385-388$.

16 Kowal DM, Patton F, Vogel JA. Psychological states and aerobic fitness of male and female recruits before and after basic training. Aviat Space Environ Med 1978; 49: 603-606.

17 Foreman PE, Cull J, Kirkby RJ. Sports participation in individuals with spinal cord injury: demographic and psychological correlates. Int J Rehabil Res 1997; 20: $159-168$.

18 Jacobs DP, Roswal GM, Horuat MA, Gorman DR. A comparison between the psychological profiles of wheelchair athletes, wheelchair nonathletes, and able-bodied athletes. In: Doll-Tepper G et al (ed). Adapted Physical Activity. Springer Verlag: Berlin 1990, pp 75-79.

19 Paulsen P, French R, Sherrill C. Comparison of wheelchair athletes and nonathletes on selected mood states. Percept Mot Skills 1990; 71: 1160-1162.

20 Figoni SF. Exercise responses and quadriplegia. Med Sci Sports Exerc 1993; 25: 433 - 441

21 Glaser RM. Exercise and locomotion for the spinal cord injured. Exerc Sports Sci Rev 1985; 13: $263-303$.

22 Berger BG, Owen DR. Stress reduction and mood enhancement in four exercise modes: swimming, body conditioning, Hatha yoga, and fencing. Res $Q$ Exerc Sport 1988; 59: $148-159$.

23 North TC, McCullagh P, Vn Tran Z. Effect of exercise on depression. Exerc Sport Sci Rev 1990; 18: 379-415. 
24 Petruzello SJ et al. A meta-analysis on the anxiety-reducing effects of acute and chronic exercise. Sports Med 1991; 11: $143-$ 182.

25 Borg G. Perceived exertion as an indicator of somatic stress. Scand J Rehabil Med 1970; 2: $92-98$.

26 Zung WWK. A self-rating depression scale. Arch Gen Psychiatry 1965; 12: $63-70$

27 Spielberger CD, Gorsuch RL, Lushene RE. Manual for the State-Trait Anxiety Inventory (STAI). Consulting Psychologist Press: California. 1970.

28 McNair DM, Lorr M, Droppleman LF. Manual for the profile of mood states. Educational and Industrial testing service: San Diego. 1971.

29 Brown RS, Ramirez DE, Taub JM. The prescription of exercise for depression. Phys Sportsmed 1978; 6: 34-49.

30 Morgan WP. A pilot investigation of physical work capacity in the depressed and nondepressed psychiatric males. Res Ouart 1969; 40: $859-862$.

31 Muraki $\mathrm{S}$ et al. Gender difference in the relationship between physical fitness and mental health. Ann Physiol Anthrop 1993; 12: $379-384$.

32 Willson VE, Morley NC, Bird EI. Mood profiles of marathon runners, joggers, and non-exercisers. Percept Mot Skills 1980; 50: $117-118$
33 Berger BG, Owen DR. Mood alteration with swimming swimmers really do 'feel better'. Psychosom Med 1983; 45: $425-433$.

34 Davis G, Plyley MJ, Shephard RJ. Gains of cardiorespiratory fitness with arm-crank training in spinally disabled men. Can $J$ Sport Sci 1991; 16: 67-72.

35 DiCarlo SE, Supp MD, Taylor HC. Effect of arm ergometry training on physical work capacity of individuals with spinal cord injuries. Phys Ther 1983; 63: 1104-1107.

36 Hooker SP, Wells CL. Effects of low- and moderate-intensity training in spinal cord-injured persons. Med Sci Sports Exerc 1989; 21: $18-22$

37 Miles DS et al. Pulmonary function changes in wheelchair athletes subsequent to exercise training. Ergonomics 1982; 25: $239-246$.

38 Hopman MTE, Dallmeijer AJ, Snoek G, van der Woude LHV. The effect of training on cardiovascular responses to arm exercise in individuals with tetraplegia. Eur J Appl Physiol 1996; 74: $172-$ 179. 